\title{
Lectin histochemistry in the human epididymis
}

\author{
M. I. Arenas ${ }^{1}$, M. P. de Miguel ${ }^{1}$, F. R. Bethencourt ${ }^{2}$, B. Fraile ${ }^{1}$, \\ M. Royuela ${ }^{\top}$ and R. Paniagua ${ }^{1 *}$ \\ ${ }^{1}$ Department of Cell Biology and Genetics, University of Alcalá de Henares, E-28871 Alcalá de Henares \\ (Madrid), Spain; and ${ }^{2}$ Department of Urology, Hospital Principe de Asturias, E-28871 Alcalá de Henares \\ (Madrid), Spain
}

\begin{abstract}
A histochemical study using lectins to identify glycoconjugates present in the efferent ducts and ductus epididymidis of men without testicular or related disease was carried out. The lectins used and the oligosaccharide residues linked were: wheat germ agglutinin (WGA) for $\beta$ - $N$-acetylglucosamine and sialic acid, concanavalin A (ConA) for $\alpha$-mannose, Llex europaeus agglutinin (UEA-I) for $\alpha$-fucose, Dolichos biflorus agglutinin (DBA) for $\alpha-N$ acetylgalactosamine, soy bean agglutinin (SBA) for $\beta$ - $N$-acetylgalactosamine, and peanut agglutinin (PNA) for $\beta$-galactose. The lectin-binding pattern in the human epididymis presents similarities and differences to those observed in other mammals which also showed differences between species. The present results revealed that regional differences along the human ductus epididymidis were less pronounced than those reported in other mammals. The epithelial cells in the efferent ducts reacted positively to WGA. All along the length of the ductus epididymidis, the principal cells and the luminal content showed staining affinity for WGA and ConA. The epididymal principal cells and luminal content also reacted positively to DBA for $\alpha-N$-acetylgalactosamine but only in the cauda epididymidis. A positive reaction to UEA-I was observed only in the luminal content of the cauda epididymidis. This finding suggests that changes in the oligosaccharide chains of secretions leading to a positive UEA-I reaction occur in the cauda epididymidis. The epididymal principal cells showed positive reactions to SBA and PNA over the apical microvilli but not in the cytoplasm. The reaction was observed in the caput and corpus epididymidis but not in the cauda. Positive reactions to SBA and PNA were also detected in the epididymal fluid and in the cytoplasm of mitochondria-rich cells (a minor population of epididymal epithelial cells). These cells also reacted to other lectins such as WGA, ConA and DBA, which were also detected in the principal cells.
\end{abstract}

\section{Introduction}

Mammalian spermatozoa are not mature when they leave the testis; their development continues during their passage through the epididymis (spermatozoon maturation) (Bedford, 1975). A contribution from the epididymis is necessary for this maturational process (Echeverria et al., 1984) and, most importantly, spermatozoa acquire the ability to fertilize in the epididymis. Although the precise region of the epididymis where this acquisition occurs varies with species, it occurs generally in the corpus or proximal cauda epididymidis (Bedford, 1975).

The ductuli efferentes are a series of tubules that conduct spermatozoa from the rete testis to the epididymis (Ilio and Hess, 1994). These tubules leave the testis, initially as parallel straight tubules containing ciliated and non-ciliated cells in an epithelium of irregular height (Saito et al., 1990; Yeung et al.,

${ }^{*}$ Correspondence and reprint requests

Received 21 September 1995.
1991). These ducts continue with the ductus epididymidis, a convoluted duct that extends from the caput to the cauda epididymidis. The epithelium lining the ductus epididymidis is columnar pseudostratified and comprises mainly principal cells and basal cells (Morita, 1966). Isolated mitochondria-rich cells (also called narrow cells, apical cells or flask cells according to their shape) may be seen in the caput and, more rarely, in the corpus epididymidis (Palacios et al., 1991). Intraepithelial lymphocytes are evident in increasing numbers as one proceeds from the caput more distally (Ritchie et al., 1984). Another epithelial cell type, designated as the clear cell, has been reported in mice and rats but not in humans (Toshimori et al., 1988). The epididymal epithelium displays regional changes in features such as luminal diameter and smooth muscle investment (Vendrely, 1981). The epididymis has been implicated in the secretion of a variety of substances ranging from small molecules to proteins (Hamilton, 1975; Turner, 1979). Biochemical analyses in various species have demonstrated the presence of specific epididymal proteins, which vary with the epididymal region (Lea $e t$ al., 1978; Echeverria $e t$ al., 
1982; Russell et al., 1984; Olson and Hinton, 1985). Synthesis and secretion of proteins and glycoproteins by the epididymal epithelium have also been demonstrated using radioautography (Kopecny and Pech, 1977) or immunocytochemical procedures (Tezon et al., 1985). Light microscope autoradiography studies have shown the greatest activity for protein or glycoprotein synthesis in the initial segment of the epididymis, with progressively lower protein incorporation in the middle and terminal segment (Kopecny and Pech, 1977). In the mouse epididymis, the synthesis and transport of proteins seem to be more rapid in the middle than in the initial segment (Flickinger, 1981).

Lectins have been used extensively as biochemical tools to isolate glycoproteins, glycolipids and polysaccharides and as probes to investigate the sugar residues of the cell surface. When conjugated to a marker, such as fluorescent dye, peroxidase or colloidal gold, lectins may be used as histochemical probes to identify and localize specific carbohydrate residues (Roth, 1978; Chang and Wong, 1992). Lectins are especially useful in studies of the quality, distribution, assembly and turnover of glycoconjugates in normal and pathological tissues, as well as during embryonic differentiation (Brown and Hunt, 1978; Lis and Sharon, 1986). Lectin histochemistry has been carried out in the epididymis of the mouse (Mus musculus), guinea-pig (Cavia porcellus), gerbil (Jaculus jaculus) and nutria (Lutra lutra) (Arya and Vanha-Perttula, 1986; Burkett et al., 1987). The results of these studies revealed positive reactions for wheat germ agglutinin (WGA), peanut agglutinin (PNA) and concanavalin $\mathrm{A}$ (ConA), although the staining pattern varied among species and among regions of the epididymis. The aim of the present study was to examine the location and distribution of glycoconjugates in the human epididymis using a number of biotinylated lectin-peroxidase complexes.

\section{Materials and Methods}

Human epididymides from 17 adult men (aged from 25 to 55 years) were obtained at autopsy (6-10 h after death). These men had died either in traffic accidents (seven men) or from myocardial (five men) or cerebral (five men) infarction. The condition for selection was that the testes showed a normal histological pattern, including complete spermatogenesis. Samples were fixed in 10\% (v/v) buffered formaldehyde for $24 \mathrm{~h}$ at room temperature. Tissue specimens were dehydrated through a graded ethanol series, cleared in xylene and embedded in paraffin wax (Paraplast: Panreac, Barcelona). Postmortem changes in the autopsy specimens were evaluated by immediately fixing and processing three epididymides obtained from testicular tumour surgery in the same way. Removal of tissues and the study of autopsy samples were approved by the Ethics Committee of the Hospital and made with the consent of the patients' relatives.

Thick sections, $5 \mu \mathrm{m}$, were cleared of paraffin with xylene and rehydrated through a series of decreasing ethanol concentrations followed by PBS. For glycoconjugate demonstration, in addition to histochemical staining with Alcian blue ( $\mathrm{pH} 2.5)$ / periodic-acid-Schiff (AB/PAS) (Mowry, 1963), different horseradish peroxidase-labelled lectins were used at concentrations of $10-20 \mu \mathrm{g} \mathrm{ml}^{-1}$ in $0.1 \mathrm{~mol} \mathrm{PBS}^{-1}$ (pH 7.2) for $60 \mathrm{~min}$ at room temperature. Previously, the endogenous peroxidase was blocked by incubation in $3 \% \mathrm{H}_{2} \mathrm{O}_{2}$. The lectins used were the following: wheat germ agglutinin (Triticum vulgare, WGA), concanavalin A (Concanavalia ensiformis, ConA), Ulex europaeus agglutinin-I (UEA-I), Dolichos biflorus agglutinin (DBA), soy bean agglutinin (Glycine max, SBA), and peanut agglutinin (Arachis hypogea, PNA). The peroxidase activity was revealed by a diaminobenzidine-hydrogen peroxide system (DAB; Sigma, Barcelona). All lectins were supplied by Sigma.

For lectin negative controls, the following saccharides were added at a final concentration of $1 \mathrm{mg} \mathrm{ml}^{-1}$ to the respective lectin solutions: $N$-acetyl-D-glucosamine for WGA, $\alpha$-methylD-mannoside for ConA, L-fucose for UEA-I, $N$-acetyl-Dgalactosamine for DBA and SBA, and $\beta$-galactose for PNA. Exposure to peroxidase and $D A B$ system without lectins was performed as an additional negative control. The reactions of certain control sections were examined with $D A B$ only to detect endogenous peroxidase activity in tissues. The sections were counterstained with Harris' haematoxylin, dehydrated, and mounted in DePex (Probus, Barcelona).

Mitochondrial-rich cells were identified in sections from the same specimens used here by means of enzymohistochemical and immunohistochemical techniques, using principally anti$\mathrm{AE} 1 / \mathrm{AE} 3$ cytokeratin antibodies, which immunoreact intensely against these cells. These techniques and the results obtained have been reported by Palacios et al. (1991).

\section{Results}

Comparison of the epididymides obtained during surgery with the autopsy specimens showed neither histological nor histochemical changes in the autopsy specimens.

$\mathrm{AB} / \mathrm{PAS}$ staining showed differential reactions in the epididymal epithelium. The luminal surfaces of the epithelial cells presented positive reaction to Alcian blue (acidic glycoproteins) in the efferent ducts and along the whole length of the ductus epididymidis. The apical cytoplasm of principal cells in the ductus epididymidis showed positive reaction to PAS (neutral glycoproteins). The luminal content of cauda epididymidis presented a strong positive reaction to Alcian blue and PAS.

The results of lectin histochemistry are summarized (Table 1). Reaction to WGA was positive in all epididymal regions. In the efferent ducts, the reactivity was localized in the supranuclear cytoplasm of the principal cells and ciliated cells (Fig. 1a, b). In the ductus epididymidis, the cytoplasm of all epithelial cell types stained diffusely with WGA (Fig. 1a, c). A positive reaction was also observed in the tubular lumen from the caput epididymidis onwards. The interstitial connective tissue and the smooth muscle tissue surrounding the tubules also stained all along the epididymis (Fig. Ib, c).

An intense reaction to ConA lectin was observed in the principal cells of the caput, corpus and cauda epididymidis and in the mitochondria-rich cells (present only in the caput and corpus epididymidis) (Fig. Id). The luminal content of the ductus epididymidis also labelled for ConA in the corpus and cauda. No positive reaction to this lectin was found in the efferent ducts. The interstitial connective tissue and the smooth muscle tissue surrounding the tubules also stained all along the epididymis.

Downloaded from Bioscientifica.com at 04/26/2023 12:50:02PM 
Table 1. Histochemistry of carbohydrates in the human epididymis

Ductus epididymidis

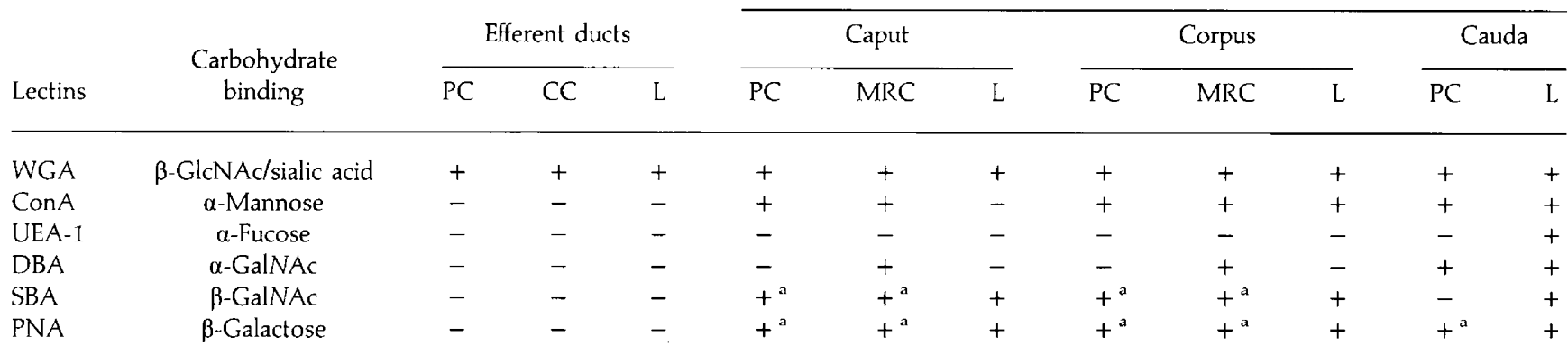

PC: principal cells; CC: ciliated cells; L: luminal fluid; MRC: mitochondria-rich cells; WGA: wheat germ agglutinin; ConA: concanavalinA; DBA: Dolichos biflorus agglutinin; SBA: soy bean agglutinin; PNA: peanut agglutinin; GlcNAc: $N$-acetylglucosamine; GalNAc: $N$-acetylgalactosamine; ${ }^{a}$ Staining is visualized only in the adluminal surface. Basal cells were labelled with WGA and only occasionally with the other lectins.

UEA-I lectin labelling was only visualized in the luminal fluid of the cauda epididymidis (Fig. 1e, f). The epithelium of the efferent ducts, caput, corpus and cauda epididymidis showed a negative reaction to this lectin.

A strong reaction to DBA was found in the mitochondriarich cells of the caput and corpus, the principal cells and luminal content of the cauda epididymidis and in fibroblast-like cells in the interstitial connective tissue throughout the epididymal length (Fig. 2a-c).

An intense reaction to SBA was observed in the luminal surface of the epithelial cells of the caput and corpus epididymidis as well as in their luminal content (Fig. 2d). The mitochondria-rich cells also presented a strong positive reaction to SBA (Fig. 2d). In the cauda, the epithelial cells showed no reaction to $\mathrm{SBA}$, whereas the luminal content reacted positively to this lectin (Fig. 2e). All along the length of the ductus epididymidis, small round cells that appeared isolated in the epididymal epithelium and, more rarely, in the interstitial connective tissue (probably lymphocytes), also reacted to SBA (Fig. 2d, e).

Reaction to PNA was localized in the luminal surface of the principal cells and luminal content in all the epididymal regions except for the efferent ducts (Fig. 2f, g). A strong label was also observed in the cytoplasm of mitochondria-rich cells (Fig. 2g).

\section{Discussion}

The lectin-binding pattern of the human epididymis obtained in the present study presents similarities and differences with regard to that observed in other mammals, such as gerbils, guinea-pigs, nutria, and mice (Arya and Vanha-Perttula, 1986; Burkett et al., 1987) which, in turn, showed differences among species. In addition, the present results reveal that regional differences along the human ductus epididymidis were less pronounced than those reported in other mammals.

In the human epididymis, a diffuse and uniformly distributed WGA labelling ( $\beta$ - $N$-acetylglucosamine and sialic acid detection) was localized in all the epithelial cells in all the epididymal segments. A positive staining to this lectin was also found in gerbils, guinea-pigs, nutria, and mice (Arya and Vanha-Perttula, 1986; Burkett et al., 1987), although only epididymal regions I and II were stained in mice, and only regions II and III were stained in nutria. The wide reaction to this lectin may be related to structural oligosaccharides. In the mouse epididymis, Burkett et al. (1987) observed a strong staining for WGA in the cilia and the apical surfaces of ciliated cells in the efferent ducts of mice. As the ciliated cells are not known to secrete macromolecules, it is more probable that newly synthesized glycoconjugates are incorporated directly into the cell plasmalemma as integral membrane glycoproteins than that they are exocytosed.

Nevertheless, WGA staining also appears in the epididymal lumen. Although the presence of stained material in the lumen and epithelial cells does not necessarily imply that the protein is secreted (it could be taken up from the lumen), it is well known that, in contrast to the absorptive function of the efferent duct epithelial cells (Ilio and Hess, 1994), the ductus epididymidis epithelium is principally involved in glycoprotein secretion (Yeung et al., 1991), and thus, the present findings suggest that some WGA-labelled glycoprotein is also secreted in the human epididymis. In the boar epididymis, Dacheaux and Dacheaux (1988) immunolabelled antagglutinin in all the principal cells of the caput and corpus epididymidis as well as in the lumen. These authors also found that antagglutinin is a sialoprotein that binds WGA and ConA in the corpus and cauda epididymidis of this species. In addition, Bedford et al. (1973), in humans, and Toshimori et al. (1988), in mice, detected sialic acid residues in spermatozoa and assumed that these residues are from the sperm maturation antigen (SMA). Toshimori et al. (1988) concluded that mouse SMA is secreted by the epididymal clear cells - and not by the principal cells because only the clear cells of the corpus epididymidis showed a positive reaction to sialic acid. In the study reported here, where WGA lectin labelled the SMA, this would not have been synthesized by the clear cells, which are absent in most mammals including humans, but by other epithelial cells. In mice, the clear cells are present only as isolated cells in the corpus epididymidis. It may be that, in humans and in some 

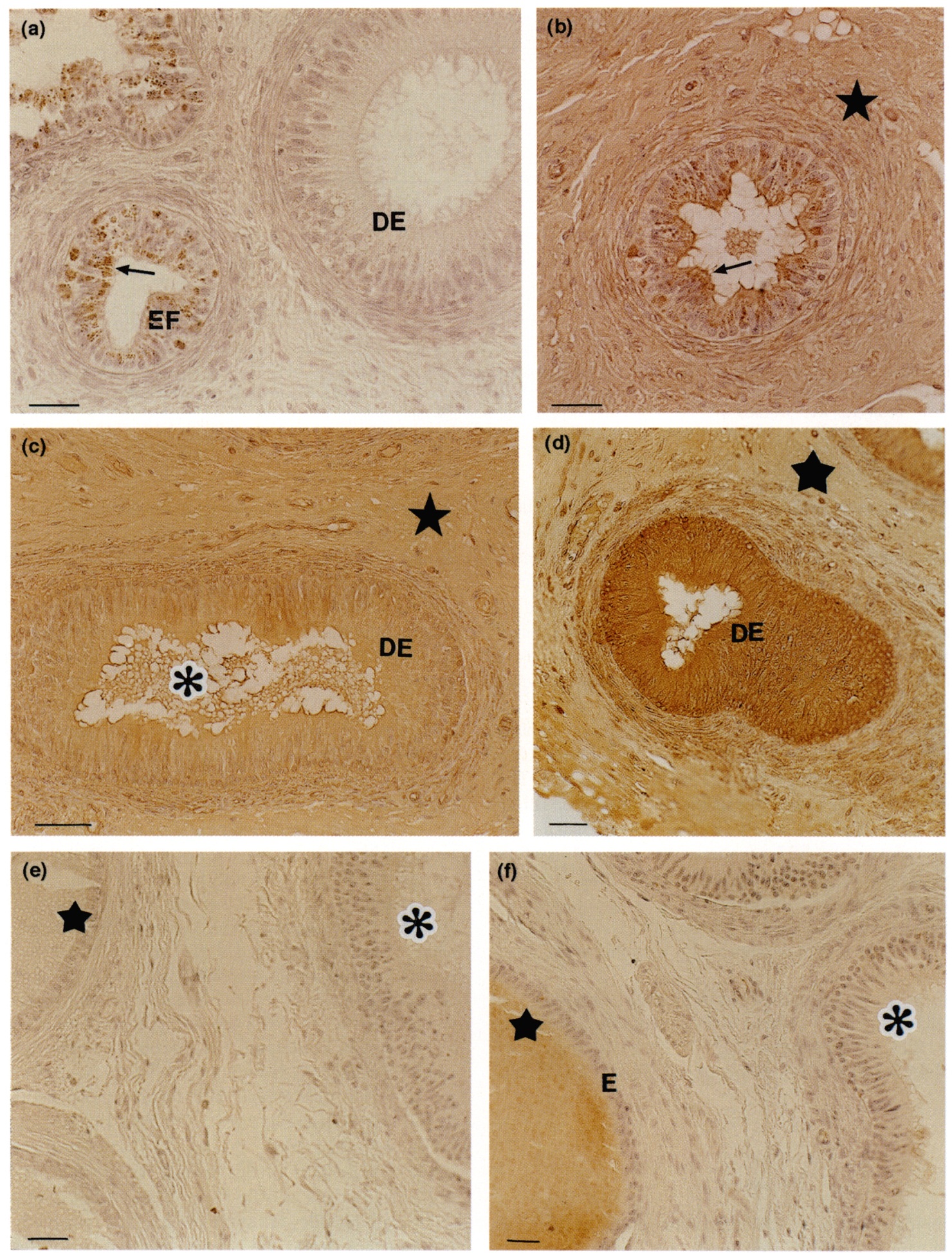

Fig. 1. (a-c) Wheat germ agglutinin staining for the demonstration of the presence of $\beta-N$-acetylglucosamine/sialic acid in the human epididymis. (a) Control section of the caput epididymidis from a 41-year-old man. Positive staining (due to peroxidase activity) is observed only in lysosomal granules (arrow) of the efferent duct epithelium (EF). DE: ductus epididymidis. (b) Efferent ducts from a 26-year-old man. In addition to the lysosomal reaction, the supranuclear cytoplasm of the epithelial cells (arrow) and the interstitial connective tissue (star) were weakly stained. (c) Caput epididymidis from a 30-year-old man. The epithelium of the ductus epididymidis (DE), luminal content (asterisk), and the connective tissue (star) are diffusely stained. (d) Concanavalin A staining for the demonstration of the presence of mannose in the corpus epididymidis from a 33-year-old man. The epithelial cells reacted intensely to this lectin (DE). A weaker reaction was observed in the connective tissue (star). (e, $f$ ) Ulex europaeus agglutinin-I staining for fucose. (e) Control section of the corpus (asterisk) and cauda (star) epididymidis from a 42-year-old man. No positive reaction is observed. (f) Corpus (asterisk) and cauda (star) epididymidis from a 39-year-old man. A positive reaction is observed only in the Iuminal content but not in the epithelium (E) of the cauda. All sections were counterstained with Harris' haematoxylin. Scale bar: $1 \mu \mathrm{m}$ for all micrographs. 

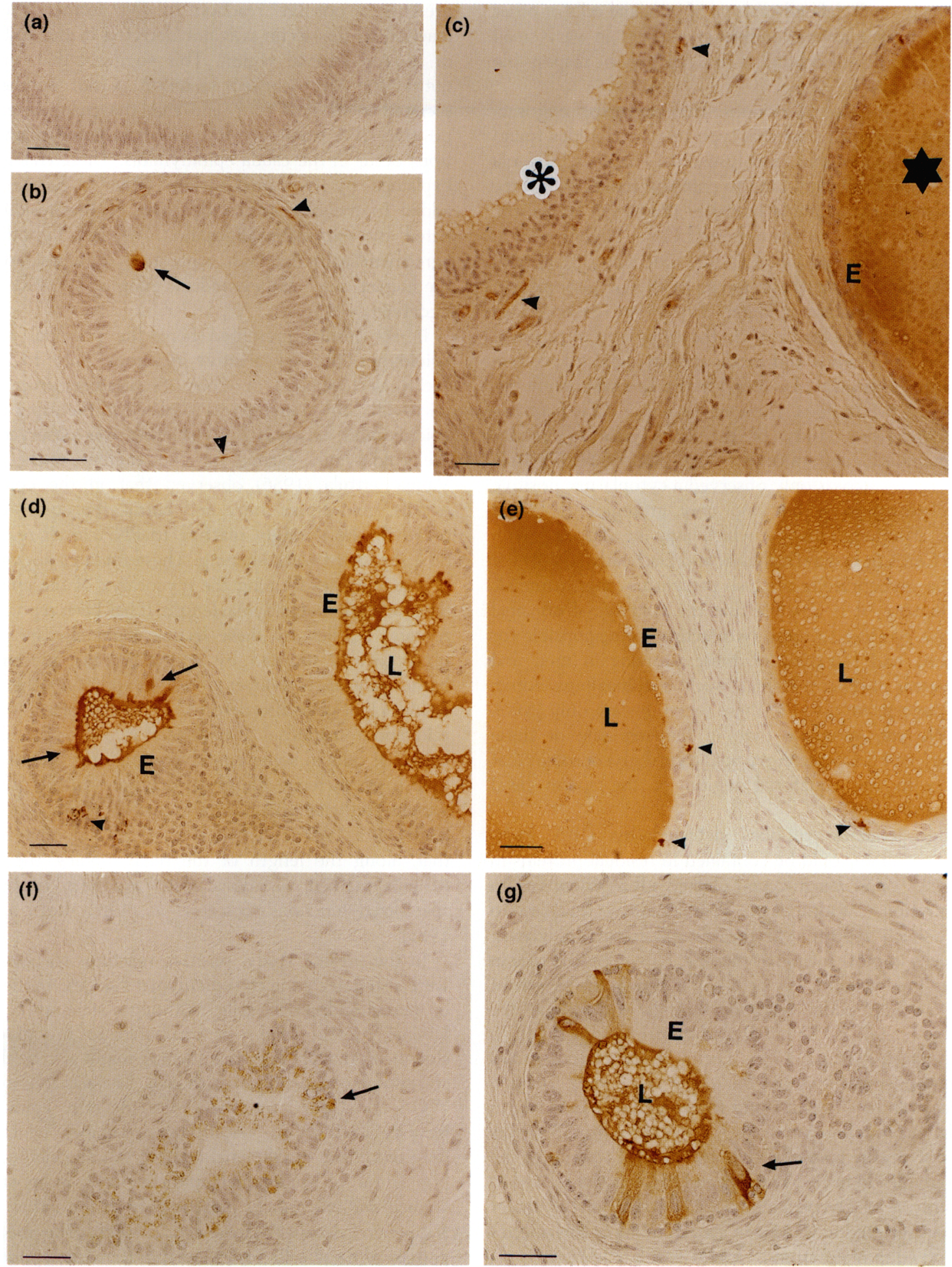

Fig. 2. (a-c) Dolichos biflorus agglutinin staining of $\alpha$-galactosamine. (a) Control section of the corpus epididymidis from a 52 -year-old man showing a negative reaction to this lectin. (b) Corpus epididymidis from a 39-year-old man. Only an isolated, apically placed, mitochondria-rich cell (arrow) appears stained in the epithelium. Some fibroblast-like cells stained in the connective tissue (arrowheads). (c) Transition from the corpus (asterisk) to the cauda (star) epididymidis from a 41-year-old man. A positive reaction was observed in the epithelial lining (E) and the luminal content of the cauda epididymidis. Fibroblast-like cells are also stained in the connective tissue (arrowheads). (d, e) Soy bean agglutinin staining for $\beta$-galactosamine. (d) Corpus epididymidis from a 37-year-old man showing an intense reaction in the luminal surface of the epithelial cells (E) and luminal content (L). Mitochondria-rich cells displaying apical locations (arrows) are also stained. The dark spots (arrowhead) in the epithelium are probably intraepithelial lymphocytes. (e) Cauda epididymidis from a 33-year-old man. Only the luminal content appears positively stained (L). The dark spots (arrowheads) in the epithelium (E) may be intraepithelial lymphocytes. ( $\mathrm{f}, \mathrm{g}$ ) Peanut agglutinin (galactose) staining for galactose in the epididymis from a 42-year-old man. (f) No reaction is observed in the efferent ducts. The dark granules (arrow) are lysosomes which also

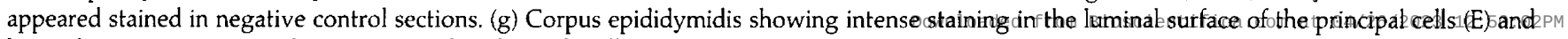
luminal content (L). Several narrow mitochondria-rich cells (numerous in this section) are also stained (arrow). All sections were counterstainedéss with Harris' haematoxylin. Scale bar: $1 \mu \mathrm{m}$ for all micrographs. 
other mammals, an ill-defined subtype of principal cells or other cell type of the epididymal epithelium present in very small numbers, such as the mitochondria-rich cell, may be responsible for this secretion.

ConA binds tightly to mannose-rich precursor oligosaccharide chains, complex mannose-type oligosaccharides found in membrane glycoproteins, and lysosomal enzymes (Shibuya et al., 1988). ConA does not bind to complex chains with three or more $\mathrm{N}$-acetylglucosamine branches (Baenziger and Fiete, 1979). Several researchers have reported ConA-binding sites in the cisternae of the rough endoplasmic reticulum (Chang and Wong, 1992), and within the cisternae of the Golgi apparatus (Roth, 1983; Pavelka and Ellinger, 1985). We observed an intense staining affinity for ConA in the cytoplasm of principal cells in the caput, corpus and cauda epididymidis. A positive reaction to this lectin was also found in the luminal content but only in the last two regions. These observations differ from the lectin histochemistry study of the epididymis of gerbils, guinea-pigs, nutria, and mice by Arya and Vanha-Perttula (1986). These researchers only observed a cytoplasmic positive reaction to ConA in gerbils and only in region II of the epididymis. If antagglutinin - which may be detected with WGA and ConA in boars (Dacheaux and Dacheaux, 1988) - or other similar glycoproteins are also present in other mammals including humans, it is possible that the epididymal principal cells that are positive to these two lectins are responsible for the synthesis and secretion of these proteins in men and gerbils, whereas in other mammals, such as guinea-pigs, nutria, and mice, the cells involved in these secretions are only WGA positive. We can speculate that, in humans, one of these proteins may be HE2, a secretory epididymal glycoprotein that associates with the equatorial region of the sperm head (Osterhoff et al., 1994).

The oligosaccharide residues detected by DBA $(\alpha-N-$ acetylgalactosamine) could be contained in residual proteins in the lysosomes or in mucin-type-O-linked glycoproteins from mucous secretions (Madrid et al., 1994). Positive reactions to DBA have been reported in the cytoplasm of epididymal epithelial cells in most mammals studied. However, whereas in guinea-pigs this reaction was positive all along the length of the ductus epididymidis, in mice, gerbils and nutria, the reaction was limited to the initial epididymal regions (I and II) (Arya and Vanha-Perttula, 1986). Lectin histochemical studies on the mouse epididymis by Burkett et al. (1987) found a positive reaction to DBA all along the epididymis, but only in basal cells. In the present study, a reaction to DBA was observed only in the epithelial cells and luminal content of the cauda epididymis. In mice, a reaction to DBA may be related to the secretion of a glycoprotein (CP27) which is the major glycoprotein secreted in the cauda epididymidis of this species that is involved in maturation of spermatozoa (Flickinger et al., 1988). However, there is no information about a similar protein in humans.

A positive reaction to UEA-I lectin, which preferentially labels terminal fucose residues located in the outer region of oligosaccharide chains (Sugii and Kabat, 1982), has been reported in the epididymal principal cells of gerbils (regions II and III), guinea-pigs (region III) and mice (regions I and II) but not in nutria (Arya and Vanha-Perttula, 1986). We observed that the luminal content of the cauda epididymidis presents a positive reaction to this lectin. However, the reaction to this lectin was not detected in the epithelial cells in any epididymal region. This suggests that, in men and nutria, the UEA-labelled secretion is not synthesized and secreted in its final form and that the changes leading to a positive UEA reaction in the oligosaccharide chains of secretions occur in the cauda epididymidis. These changes may be explained by two mechanisms: either a fucose residue is added to the oligosaccharide chain or this residue is eliminated by enzymatic digestion. The last hypothesis is in agreement with the high content of $\alpha$-glucosidase found in the human cauda epididymidis (Yeung et al., 1990; Purvis and Egdetveit, 1993).

In the results presented here, the principal cells of the epididymis showed positive reactions only to SBA ( $\beta-N$ acetylgalactosamine) or PNA ( $\beta$-galactose) over the apical microvilli. SBA staining was localized in the caput and corpus epididymidis, whereas PNA staining was observed all along the epididymis, except for the efferent ducts. Arya and Vanha-Perttula (1986) observed that in the epididymis of gerbils, guinea-pigs, mice and nutria, the apical surface and microvilli are strongly reactive to PNA in all regions, while SBA displayed weak staining. These findings suggest that the glycoconjugates forming the glycocalyx of the epithelial cells differ along the epididymal length. It has been reported that the residues labelled by these lectins could also be part of the glycoproteins secreted by epithelial cells as cementing or barrier substances (Meyer, 1986). In addition, other saccharide residues that were also detected in the cytoplasm, such as sialic acid and $\alpha$-mannose, also appear in the glycocalyx of the epithelial cells in some epididymal regions. Lectins have been used to characterize the glycoconjugates in the glycocalyx of various epithelial cells bearing microvilli (Roth, 1983; Gonnella and Neutra, 1985; Tanimura et al., 1987) and, it has been shown that, along the length of the renal tubules, the glycocalyx exhibits marked variations that have been related to their specialized functions (Spicer et al., 1981; Roth and Taatjes, 1985).

In the present study, positive reactions to SBA and PNA were also detected in the epididymal fluid and in the cytoplasm of mitochondria-rich cells. Although staining of the intraluminal content might be attributed to the glycocalyx of sloughed principal cells, this staining might also be the result of secretion by mitochondria-rich cells. These cells also reacted to WGA and ConA, and they were the only epididymal cells positive to DBA ( $\alpha-N$-acetylgalactosamine), which was also detected in the intraluminal content. These cells form a minor population of epididymal epithelial cells in most mammals studied and are usually present only in the initial epididymal segments (Martínez-García et al., 1995). The morphological pattern of these cells varies, even in the same epithelium, from slender cells (narrow cells) to round apical cells without apparent connection with the epithelial basal lamina (apical cells); but they all contain short microvilli and an electrondense cytoplasm with abundant mitochondria (mitochondriarich cells). Histochemical and biochemical studies have also shown differences between these cells and the principal cells in the epididymis with respect to enzymatic activities and intermediate filament types (Palacios et al., 1991). Although the function of the apical mitochondria-rich cells is unknown, the 
following possible functions have been suggested: holocrine secretion (Martan and Risley, 1963), cooperation with the principal cells in reabsorption of testicular fluid (Sun and Flickinger, 1980), and acidification of epididymal fluid (Kierszenbaum et al., 1981). The present results suggest that human mitochondria-rich cells are also secretory cells responsible for a secretion that reacts to SBA and PNA and, perhaps, to WGA, ConA and DBA. These secretions probably vary from one species to another since lectin studies in mice, gerbils, nutria and guinea-pigs indicated that the mitochondria-rich cells are WGA- and ConA-positive in the four species: SBA is positive in mice, gerbils and nutria; PNA is positive in mice, gerbils and guinea-pigs; DBA is positive in gerbils and guineapigs and UEA is positive in mice (Arya and Vanha-Perttula, 1986).

The small intraepithelial and interstitial cells that react with SBA are probably lymphocytes. These cells, present in small numbers, are a normal constituent of epididymal epithelium (Ritchie et al, 1984). In the samples used in this study, we did not observe inflammatory infliltrates into the epithelium or interstitium.

This work was supported by a grant from the 'Fondo de Investigaciones Sanitarias de la Seguridad Social', Madrid, Spain.

\section{References}

Arya M and Vanha-Perttula T (1986) Comparison of lectin-staining pattern in testis and epididymis of gerbil, guinea pig, mouse, and nutria American Journal of Anatomy 175 449-469

Baenziger JU and Fiete D (1979) Structural determinants of concanavalin. A specificity for oligosaccharides Journal of Biological Chemistry 254 24002407

Bedford IM (1975) Maturation, transport, and fate of spermatozoa in the epididymis. In Handbook of Physiology, Section 7 Endocrinology Vol. V Male Reproductive System pp 303-317 Eds DW Hamilton and EB Astwood. American Physiological Society, Washington

Bedford JM, Calvin HI and Cooper GW (1973) The maturation of spermatozoa in the human epididymis Journal of Reproduction and Fertility Supplement 18 199-213

Brown JC and Hunt RC (1978) Lectins International Review of Cytology 52 $277-349$

Burkett BN, Schulte BA and Spicer SS (1987) Histochemical evaluation of glycoconjugates in the male reproductive tract with lectin-horseradish peroxidase conjugates: II. Staining of ciliated cells, basal cells, flask cells, and clear cells in the mouse American Journal of Anatomy 178 23-29

Chang $\mathrm{L}$ and Wong XC (1992) Localization of prostatic glycoconjugates by the lectin-gold method Acta Anatomica $143 \quad 27-40$

Dacheaux F and Dacheaux JL (1988) Immunocytochemical localization of antagglutinin in the boar epididymis Cell and Tissue Research $\mathbf{2 5 2}$ 329-337

Echeverria FG, Cuasnicu PS and Blaquier JA (1982) Identification of androgendependent glycoproteins in the hamster epididymis and their association with spermatozoa journal of Reproduction and Fertility 64 1-7

Echeverria FG, Cuasnicu PS, Piazza A, Piñeiro L and Blaquier JA (1984) Addition of an androgen-free epididymal protein extract increases the ability of immature hamster spermatozoa to fertilize in vivo and in vitro Journal of Reproduction and Fertility 71 433-437

Flickinger CJ (1981) Regional differences in synthesis, intracellular transport, and secretion of protein in the mouse epididymis Biology of Reproduction 25 $871-883$

Flickinger CJ, Herr JC and Kotz KL (1988) Immunocytochemical localization of the major glycoprotein of epididymal fluid from the cauda in the epithelium of the mouse epididymis Cell and Tissue Research 251 603-610
Gonnella PA and Neutra MR (1985) Glycoconjugate distribution and mobility in apical membranes of absorptive cells of suckling rat ileum in vivo Anatomical Record 213 520-528

Hamilton DW (1975) Structure and function of the epithelium lining the ductuli efferentes, ductus epididymidis, and ductus deferens in the rat. In Handbook of Physiology Section 7 Endocrinology Vol. V Male Reproductive System pp 259-301 Eds Hamilton DW and Greep RO. American Physiological Society, Washington

Ilio KY and Hess RA (1994) Structure and function of the ductuli efferentes: a review Microscopy Research and Technique 29 432-467

Kierszenbaum Al, Lea O, Petrusz P, French FS and Tress LL (1981) Isolation, culture and immunohistochemical characterization of epididymal epithelial cells from pubertal and adult rats Proceedings National Academy of Sciences USA 78 1675-1679

Kopecny V and Pech V (1977) An autoradiographic study of macromolecular syntheses in the epithelium of the ductus epididymis in the mouse. II. Incorporation of L-fucose- $\mathrm{I}^{3} \mathrm{H}$ Histochemistry $\mathbf{5 0} 229-238$

Lea OA, Petrusz P and French FS (1978) Purification and localization of acidic epididymal glycoprotein (AEG): a sperm coating protein secreted by the rat epididymis International Journal of Andrology Supplement 2 592-607

Lis H and Sharon N (1986) Lectins as molecules and as tools Annual Review of Biochemistry 55 35-67

Madrid JF, Castells MT, Martínez-Menárguez JA, Avilés M, Hernández F and Ballesta J (1994) Subcellular characterization of glucoproteins in the principal cells of human gallbladder. A lectin cytochemical study Histochemistry 101 195-204

Martan JP and Risley P (1963) Holocrine secretory cells of the rat epididymis Anatomical Record 146 173-189

Martínez-García P, Regadera J, Cobo P, Paniagua R and Nistal M (1995) The apical mitochondria-rich cells of the mammalian epididymis Andrologia 27 195-206

Meyer W (1986) Die Haut des Schweines-Vergleichende histologische und histochemische Untersuchungen an der Haut von Wildschweinen Hausschweinen und Kleinschweinen pp 1-228 Schlütersche, Hannover

Morita I (1966) Some observations on the fine structure of the human ductuli efferentes Archives of Histology Japonica 26 341-356

Mowry RW (1963) The special value of methods that colour with acidic and vicinal hydroxyl groups in the histochemical study of mucins. With revised directions for the colloidal iron stain, the use of Alcian blue 8GX and their combination with the periodic acid-Schiff reaction Annals of the New York Academy of Sciences 106 402-423

Olson GE and Hinton BT (1985) Regional differences in luminal fluid polypeptides of the rat testis and epididymis revealed by two-dimensional gel electrophoresis Journal of Andrology 6 20-34

Osterhoff C, Kirchohoff C, Krull N and Ivell R (1994) Molecular cloning and characterization of a novel human sperm antigen (HE2) specifically expressed in the proximal epididymis Biology of Reproduction 50 516-525

Palacios J, Regadera J, Nistal M and Paniagua R (1991) Apical mitochondria-rich cells in the human epididymis: an ultrastructural, enzymohistochemical, and immunohistochemical study Anatomical Record 231 82-88

Pavelka M and Ellinger A (1985) Localization of binding sites for concanavalin A, Ricinus communis I and Helix pomatia lectin in the Golgi apparatus of rat small intestinal absorptive cells Journal of Histochemistry and Cytochemistry 33 905-914

Purvis K and Egdetveit I (1993) Segmental distribution of $\alpha$-glucosidase, ornithine decarboxylase and polyamines in the human epididymis journal of Reproduction and Fertility 97 575-580

Ritchie AWS, Hargreave TB, James K and Chisholm GD (1984) Intraepithelial lymphocytes in the normal epididymis. A mechanism for tolerance to sperm auto-antigens? British Journal of Urology 56 79-83

Roth J (1978) The lectins: molecular probes in cell biology and membrane research Experimental Pathology Supplement 3 1-186

Roth J (1983) Application of lectin-gold complexes for electron microscopic localization of glycoconjugates on thin section Journal of Histochemistry and Cytochemistry 31 987-999

Roth J and Taatjes DJ (1985) Glycocalyx heterogeneity of rat kidney urinary tubule: demonstration with a lectin-gold technique specific for sialic acid European Journal of Cell Biology 39 449-457

Russell LD, Peterson RN, Hunt W and Strack LE (1984) Post-testicular modifications and contributions of reproductive tract fluids to the surface polypeptide composition of boar spermatozoa Biology of Reproduction $\mathbf{3 0}$ 959-978 
Saito K, Terada T and Hatakeyama S (1990) A morphological study of the efferent ducts of the human epididymis International Journal of Andrology 13 369-376

Shibuya N, Goldstein IJ, Van Damme EJM and Peumans WJ (1988) Binding properties of a mannose specific lectin from the snowdrop (Galanthus nivalis) bulb Journal of Biological Chemistry $263728-734$

Spicer SS, Baron DA, Sato A and Schutle BA (1981) Variability of cell surface glycoconjugates. Relation to differences in cell function Journal of Histochemistry and Cyfochemistry $29994-1002$

Sugii S and Kabat EA (1982) Further immunochemical studies of the combining sites of Lotus tetragonolobus and Ulex europaeus I and II lectins Carbohydrate Research 99 99-101

Sun EL and Flickinger CJ (1980) Morphological characteristics of cells with apical nuclei in the initial segment of the adult rat epididymis Anatomical Record 196 285-293

Tanimura F, Morioka H and Tachibana M (1987) Glycoconjugates in the glycocalyx of the guinea pig middle ear mucosa as revealed by postembedding staining with lectin gold complexes Acta Histochemica et Cytochemica $20315-320$
Tezon JG, Ramella E, Cameo MS, Vazquez MH and Blaquier JA (1985) Immunochemical localization of secretory antigens in the human epididymis and their association with spermatozoa Biology of Reproduction 32 591-597

Toshimori K, Araki S and Öura C (1988) Masking of sperm maturation antigen by sialic acid in the epididymis of the mouse. An immunohistochemical study Histochemistry 90 195-200

Turner TT (1979) On the epididymis and its function Investigations in Urology $16311-321$

Vendrely E (1981) Histology of the epididymis in the human adult. In Progress in Reproductive Biology. Vol. 8 Epididymis and Fertility: Biology and Pathology p 21 Eds C Bollack and A Clavert. Karger, Basel

Yeung $\mathrm{CH}$, Cooper TG and Senge T (1990) Histochemical localization and quantification of a-glucosidase in the epididymis of men and laboratory animals Biology of Reproduction 42 669-676

Yeung CH, Cooper TG, Bergmann M and Schulze H (1991) Organization of tubules in the human caput epididymidis and the ultrastructure of their epithelia American Journal of Anatomy $191261-279$ 